
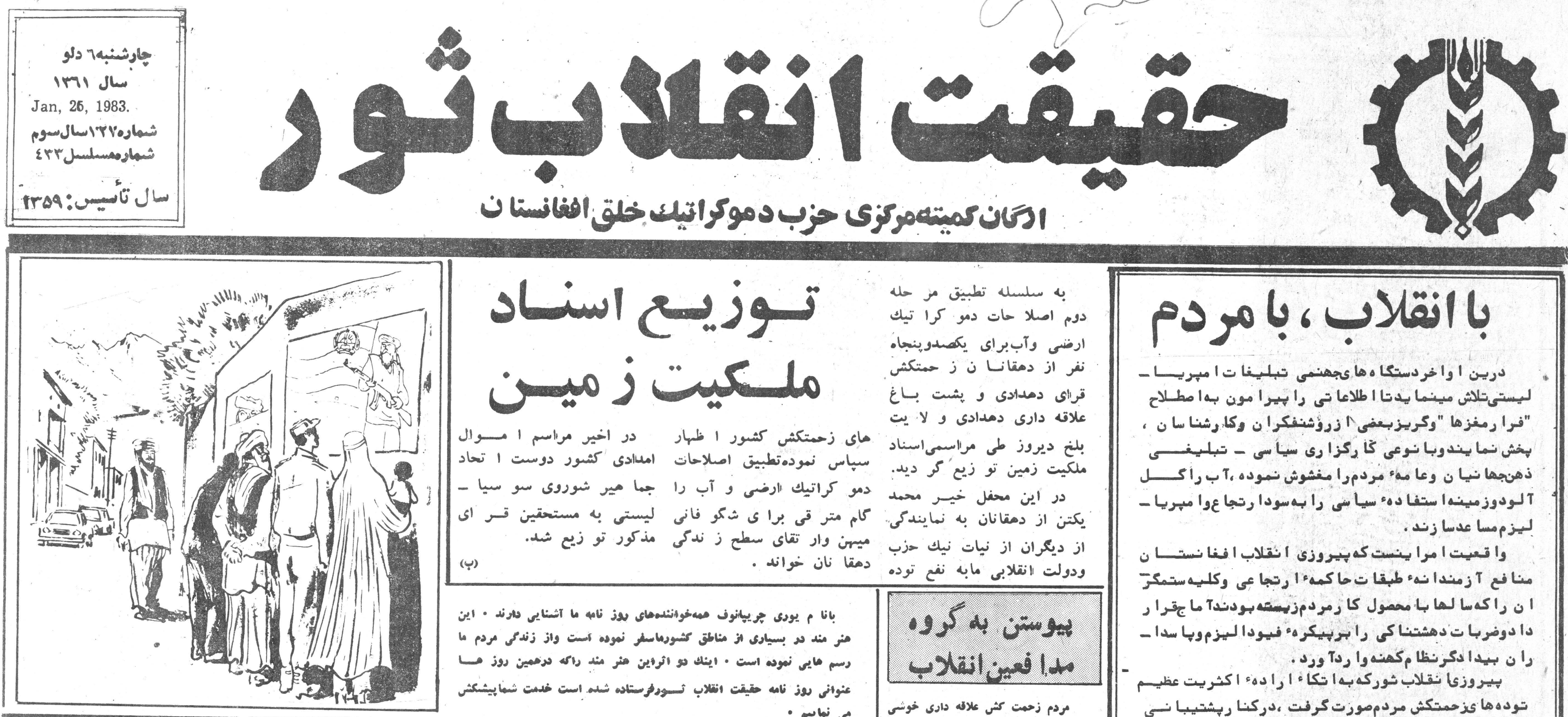

\title{
توزيدع اسنهاد
}

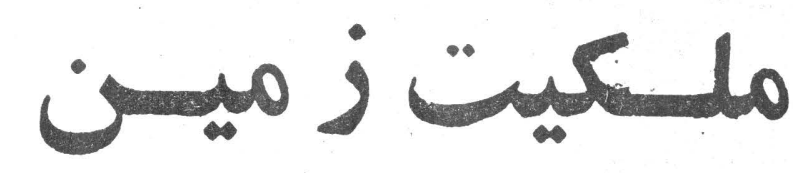

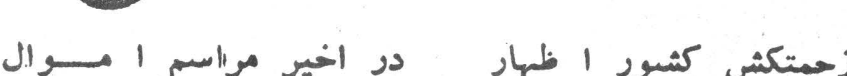

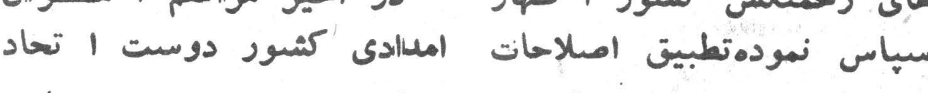

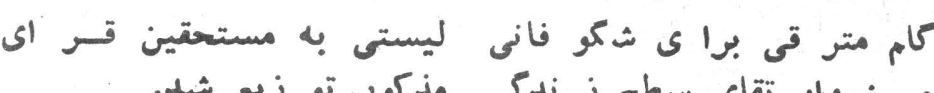

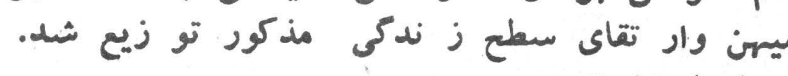

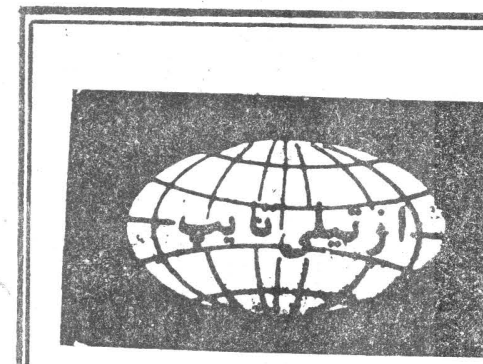

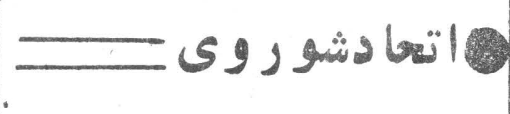

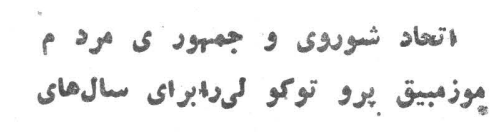

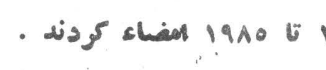

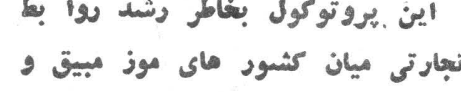

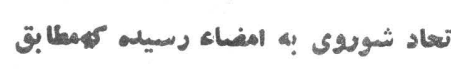

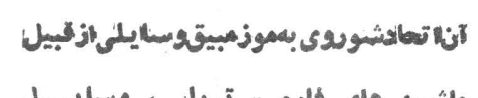

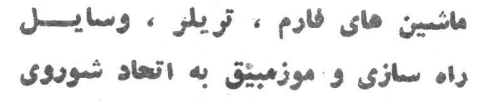

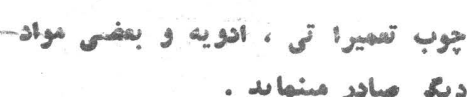

ميات هاى هزب كمو نست بلفا ريا

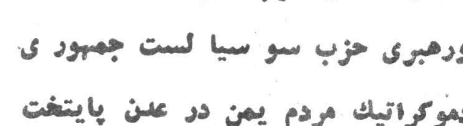

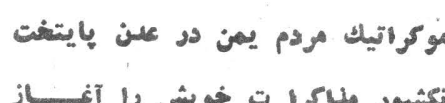

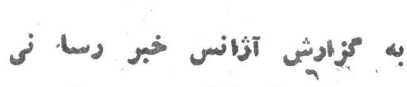

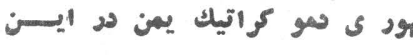

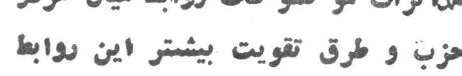

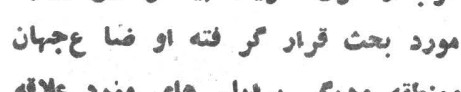

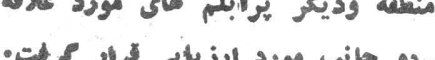

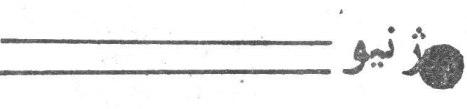
جلسه خام وزداى نمت كشور هاى

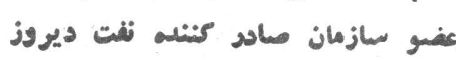

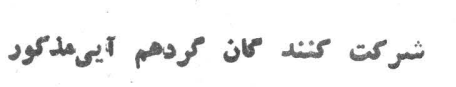

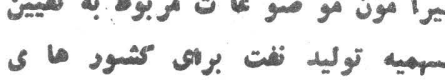

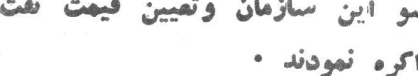

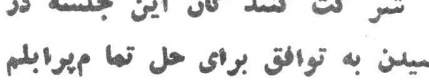

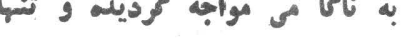

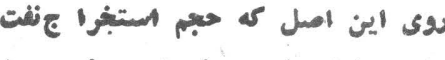

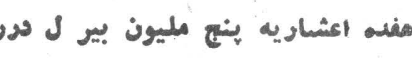

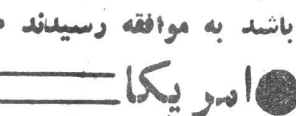
بروفيسود كر ستين بر نارد جراح

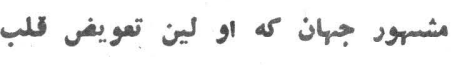

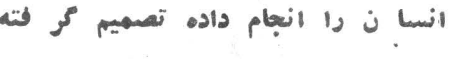

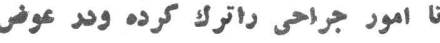

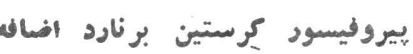

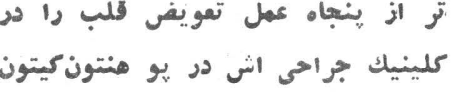

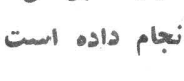

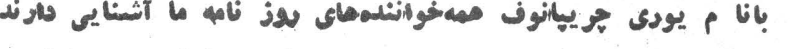

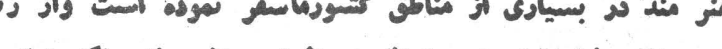

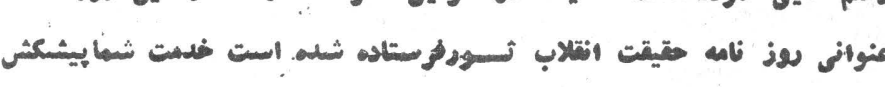

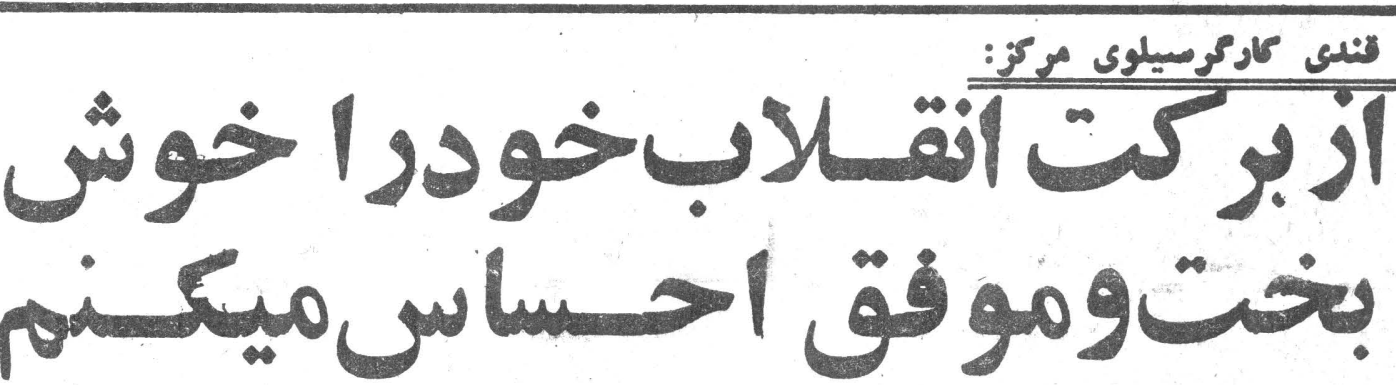

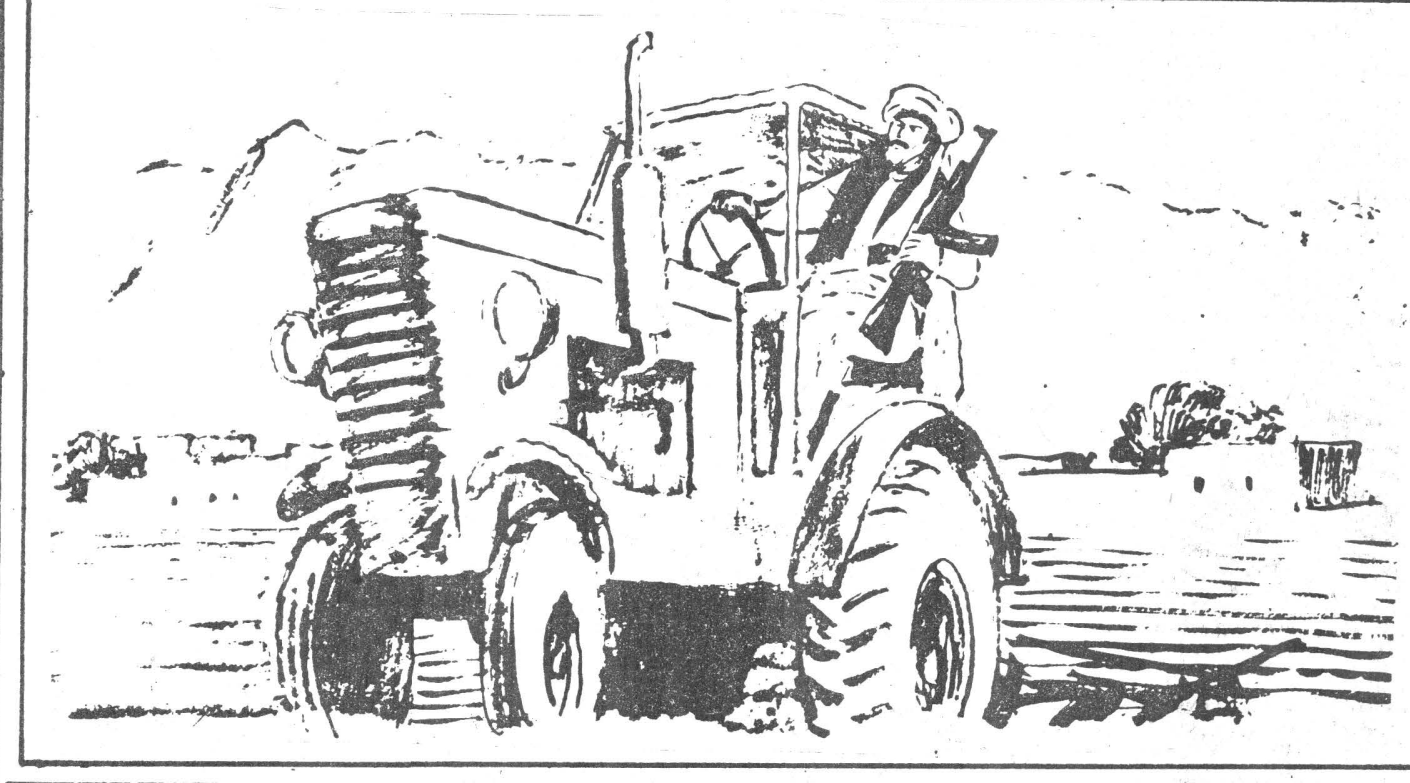

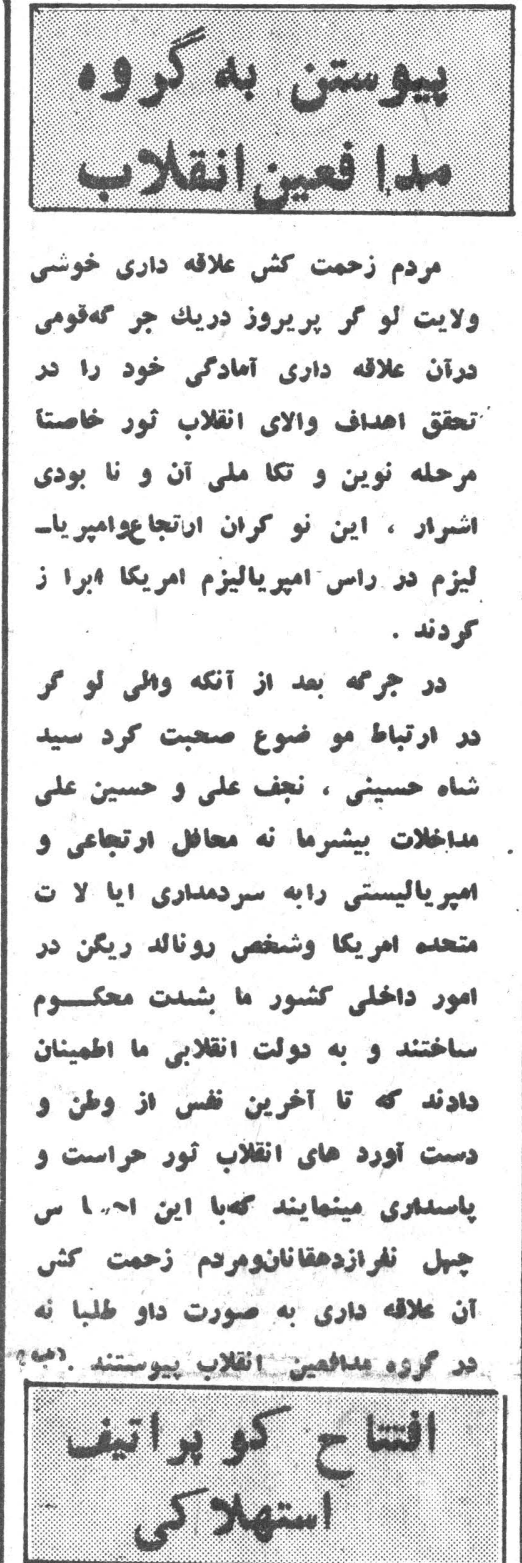

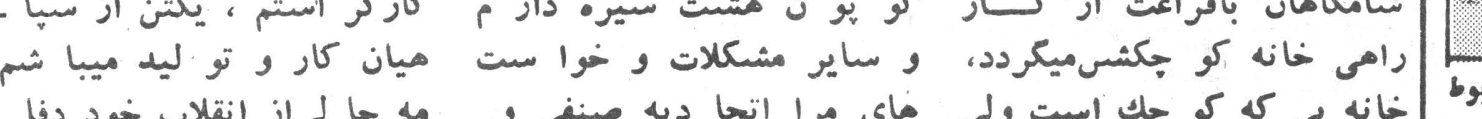

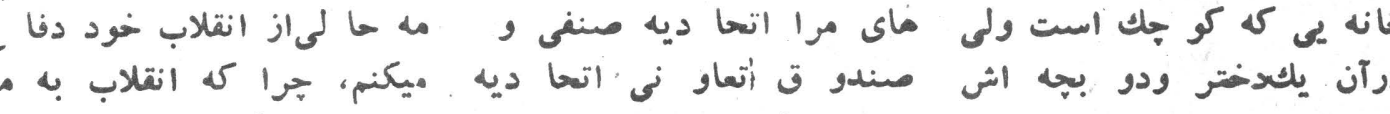

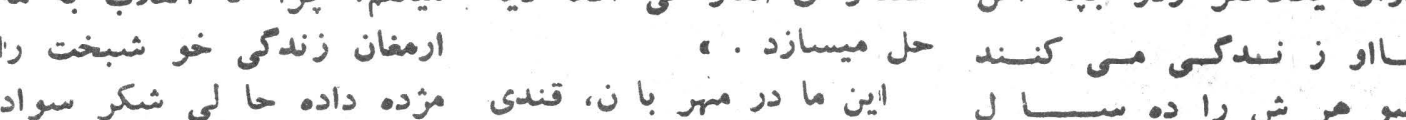

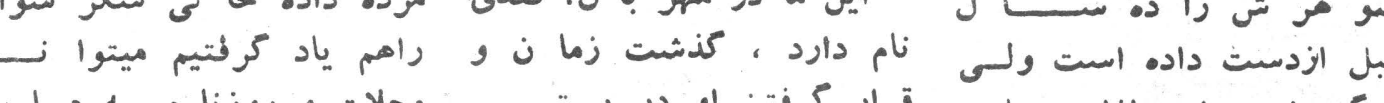

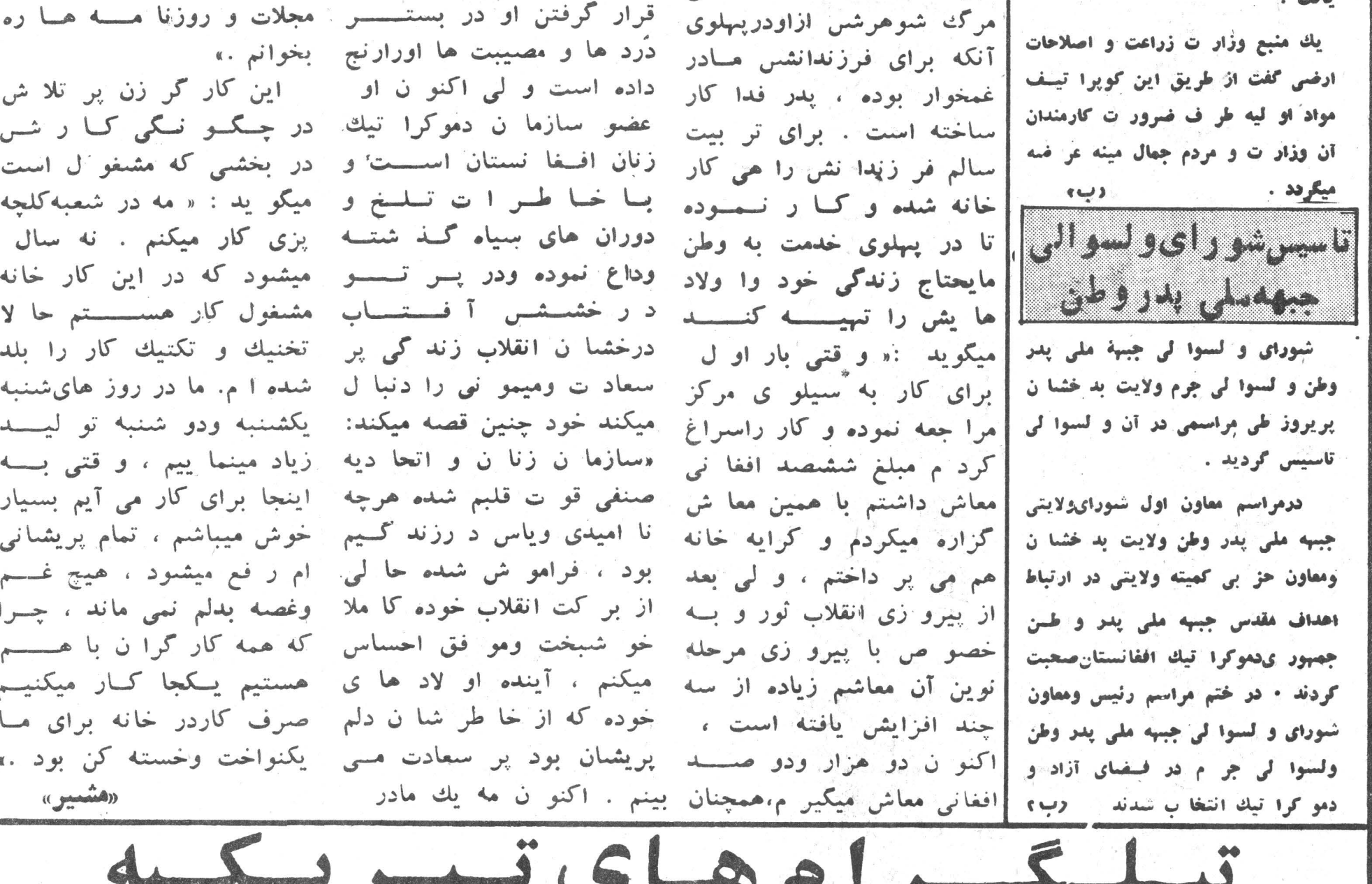

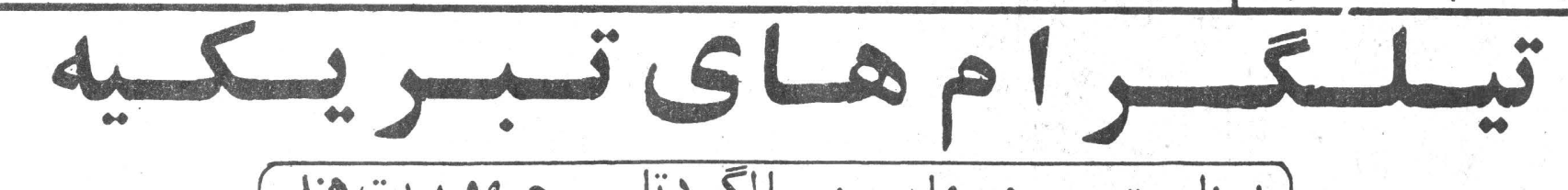

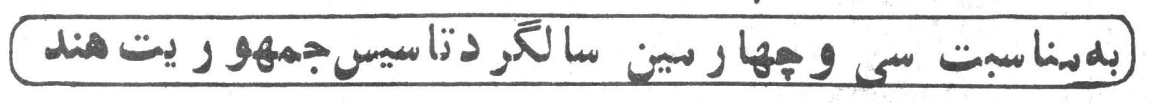

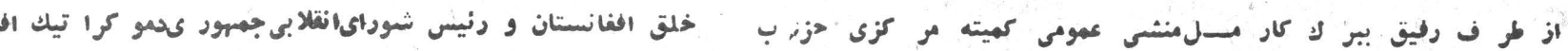

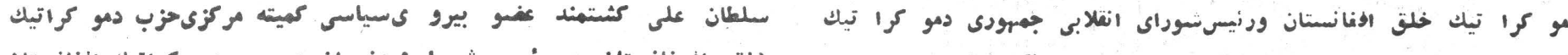

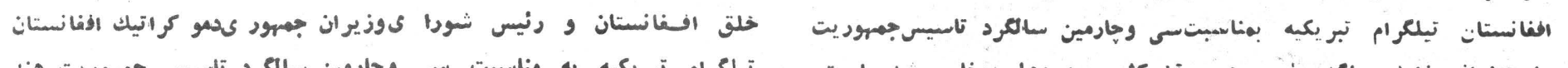

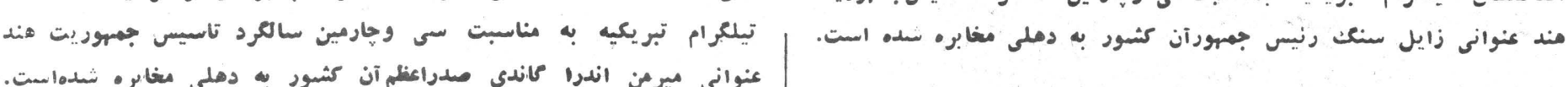

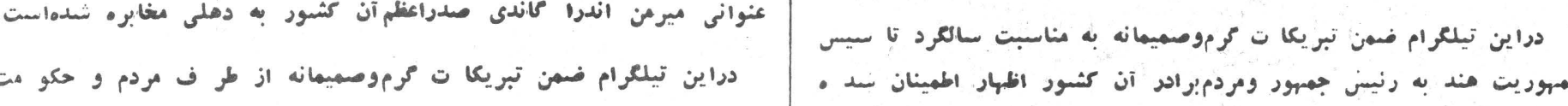

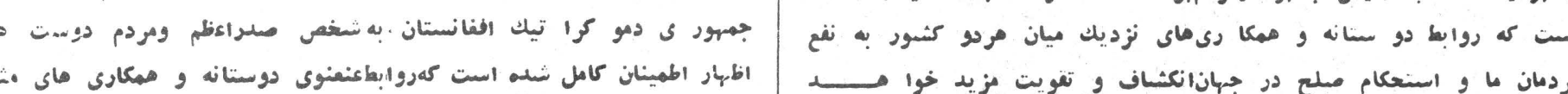

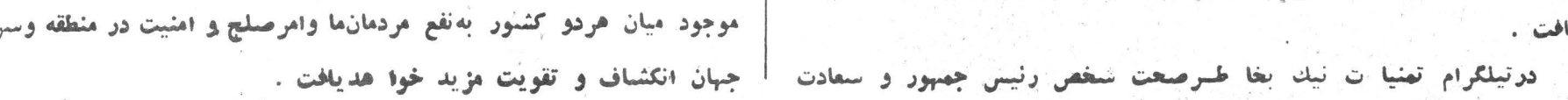

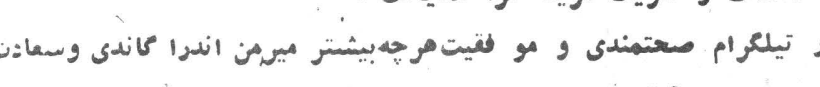

\section{با بانقلاب ، با مردم}

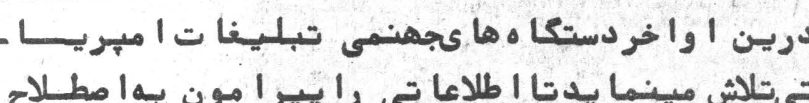

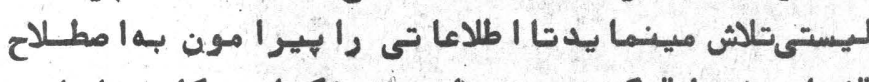

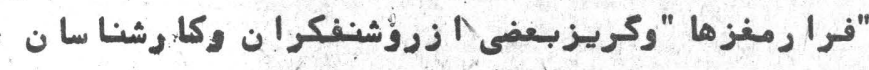

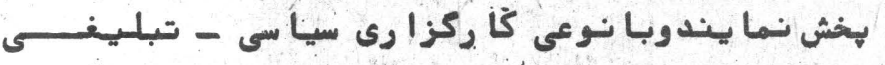

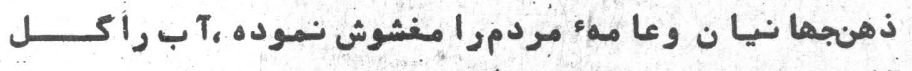

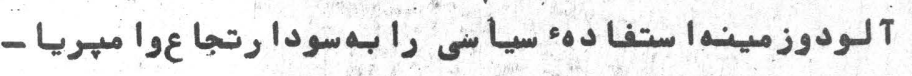

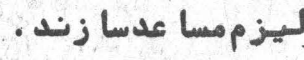

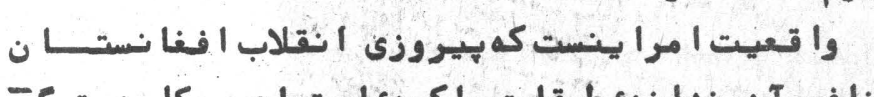

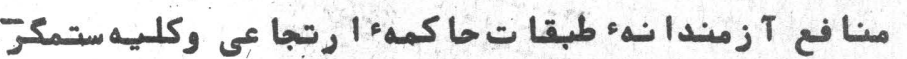

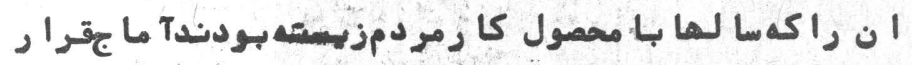

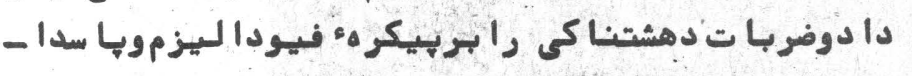

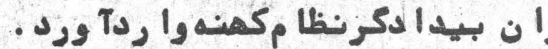

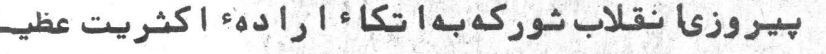

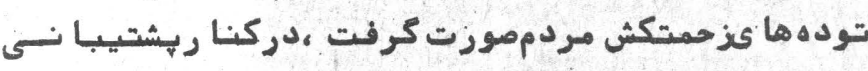

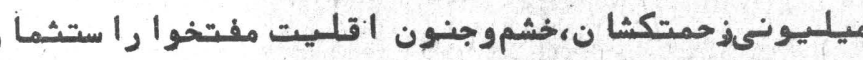

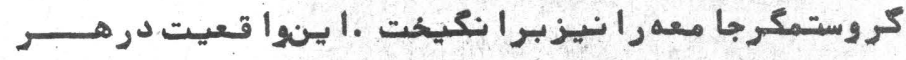

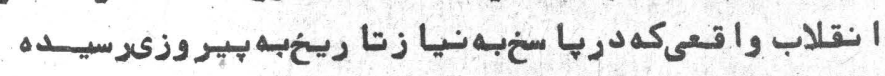

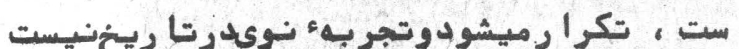

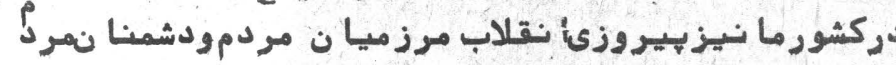

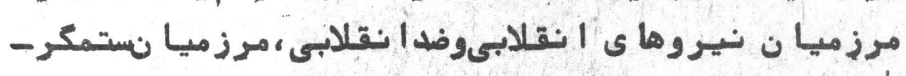

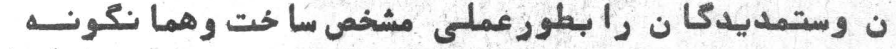

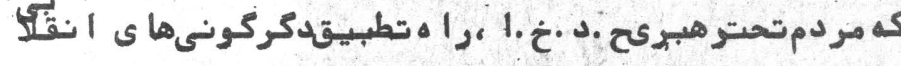

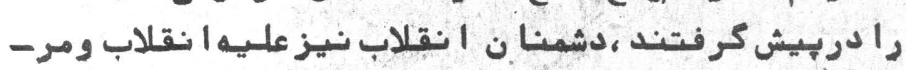

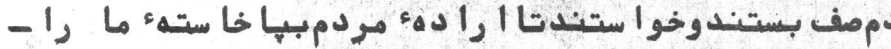

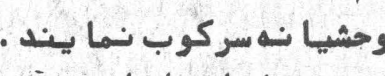

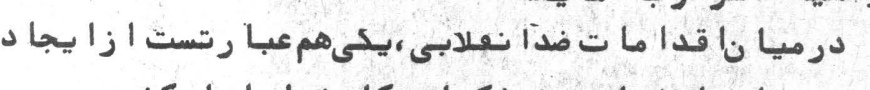

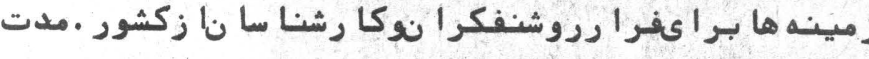

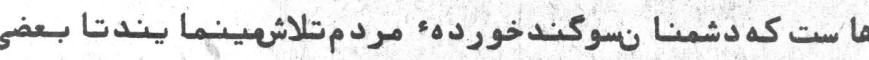

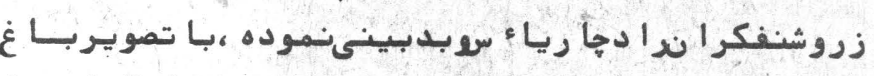

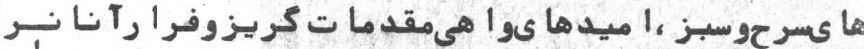

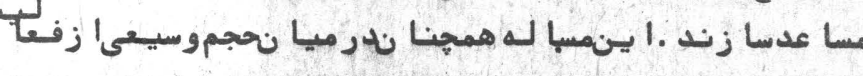

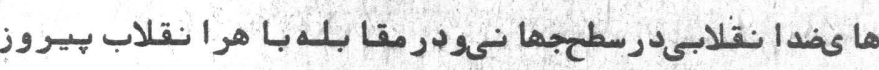

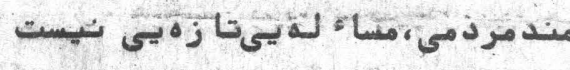

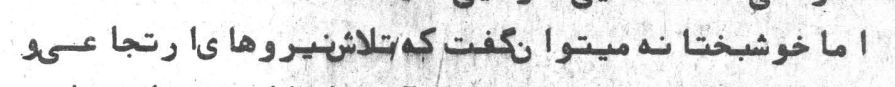

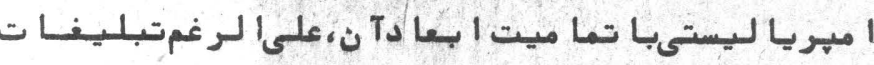

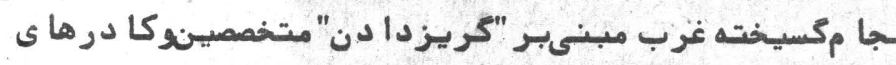

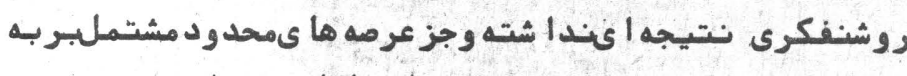

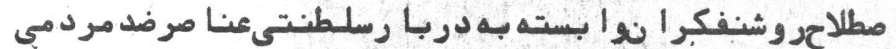

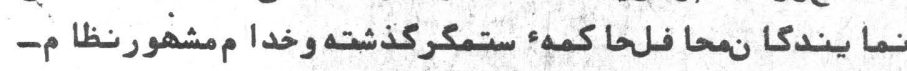

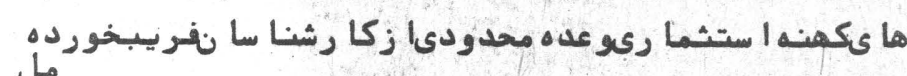

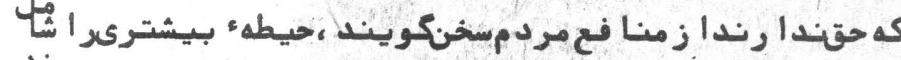

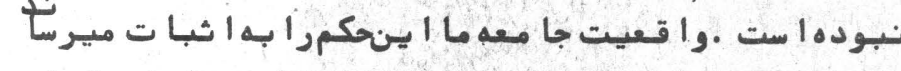

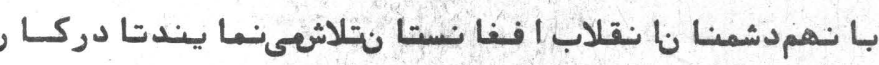

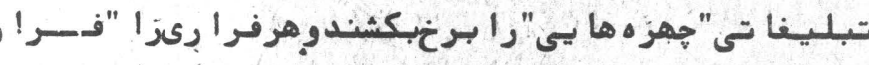

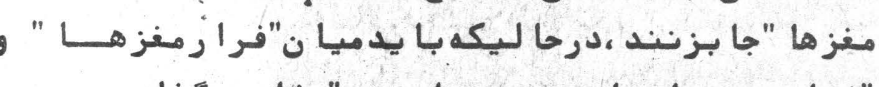

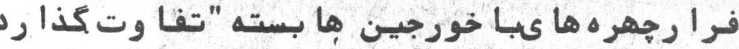

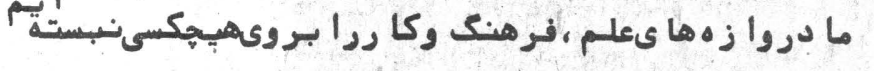

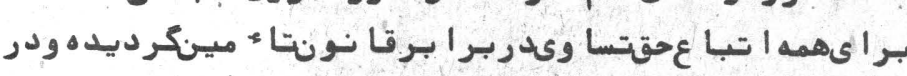

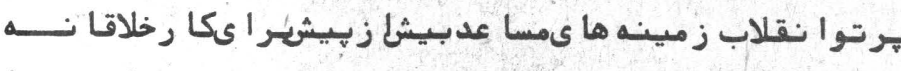

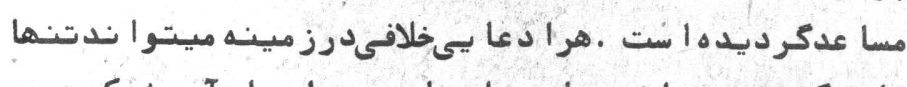

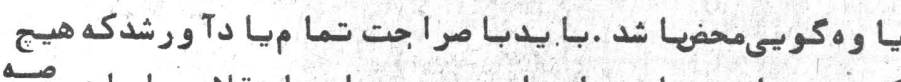

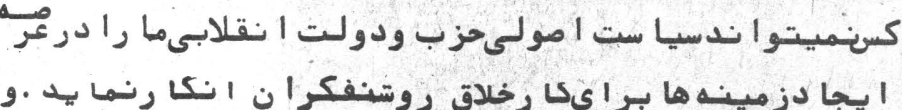

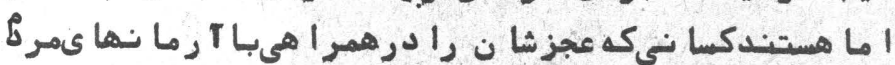

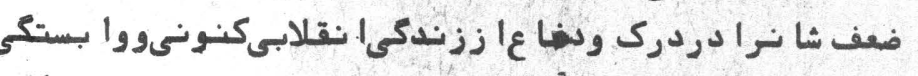

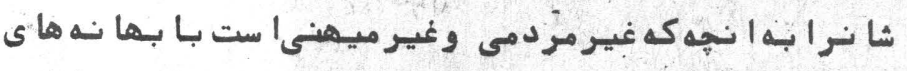

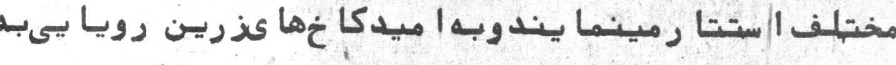

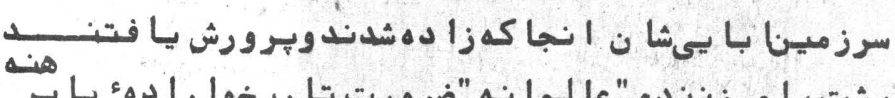

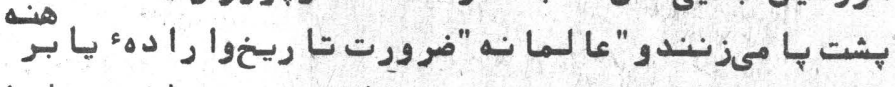

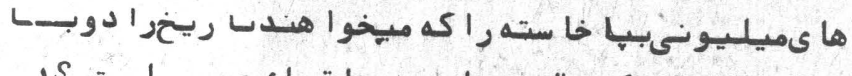

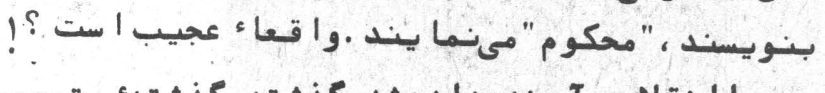

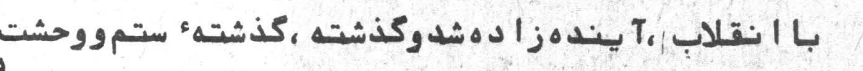

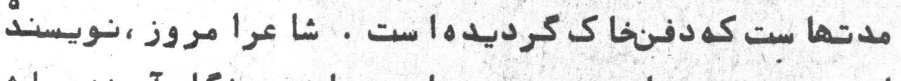

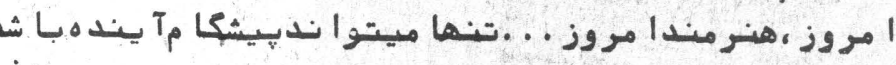

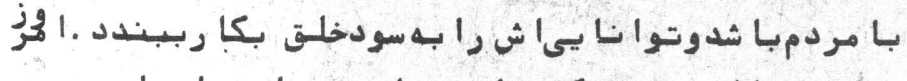

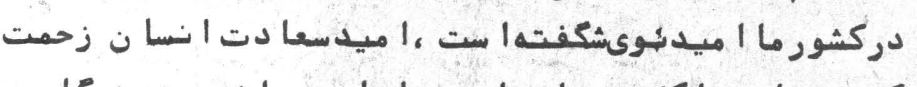

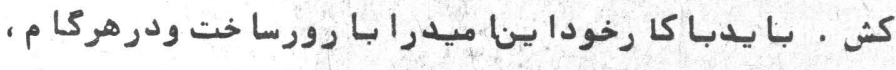

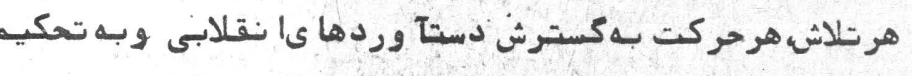

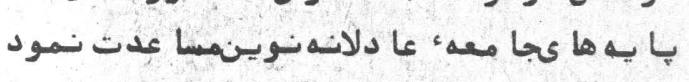

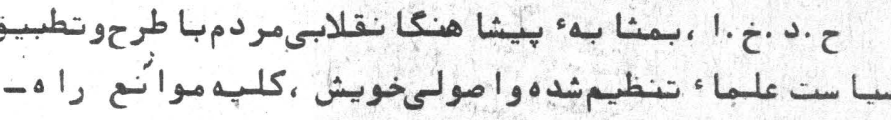

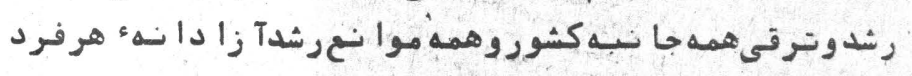

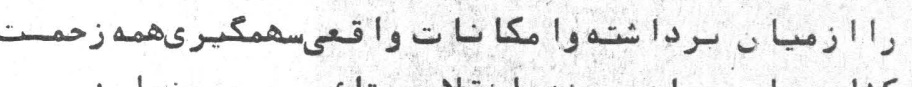

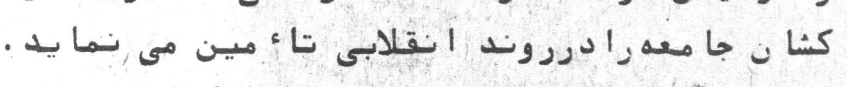

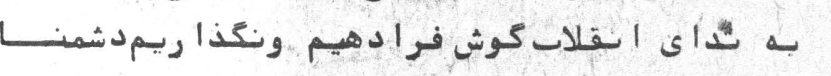




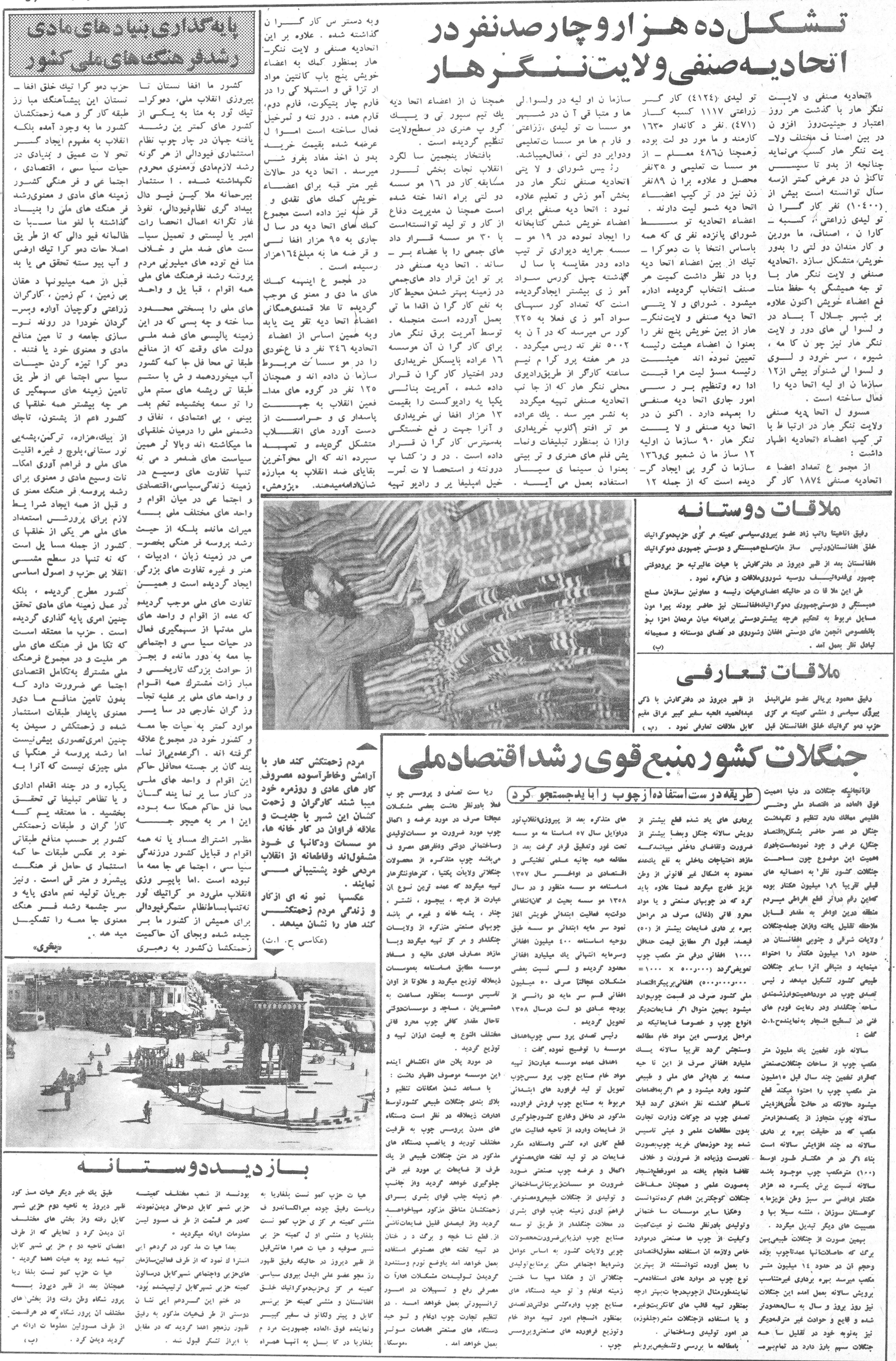




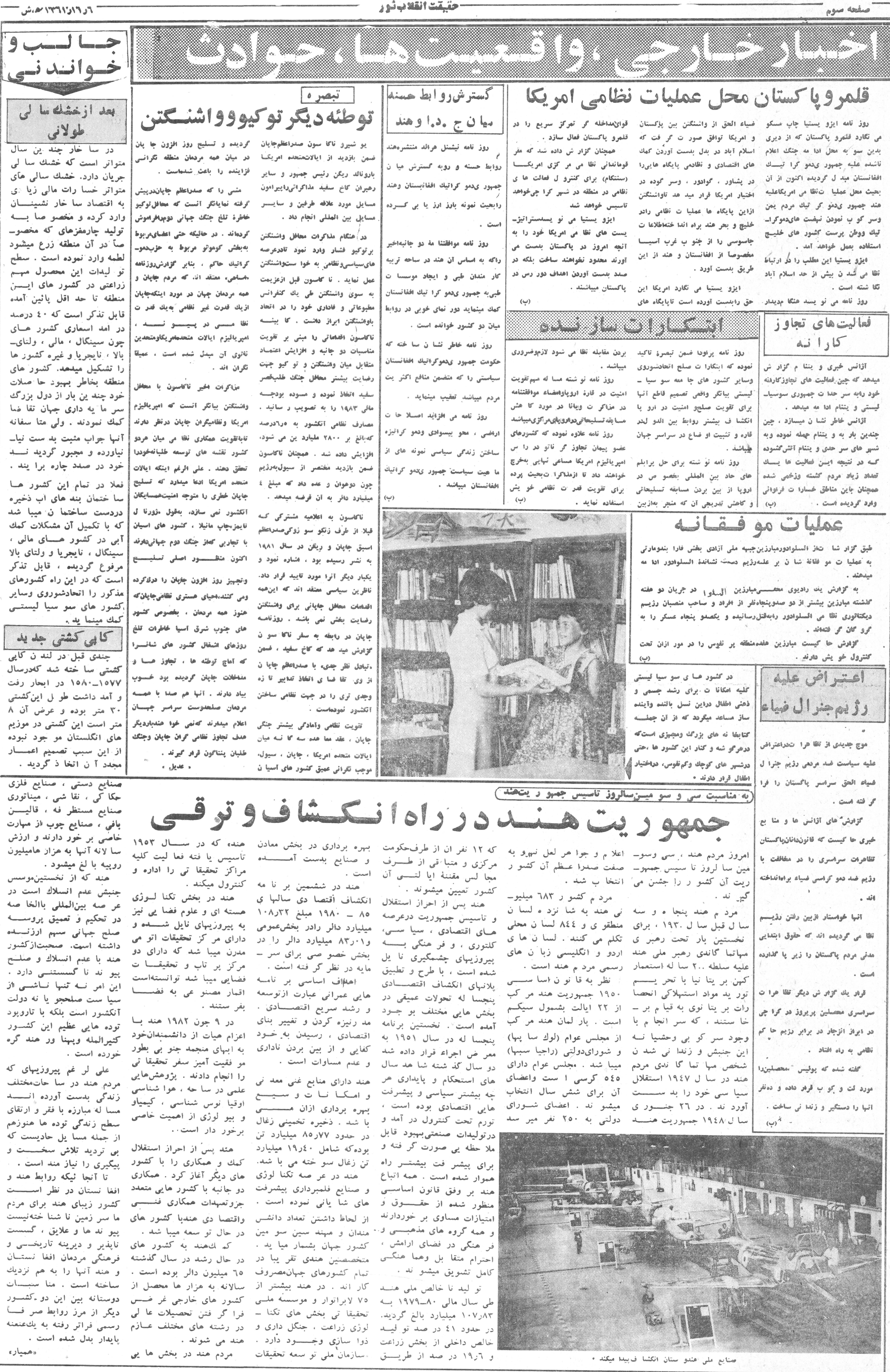




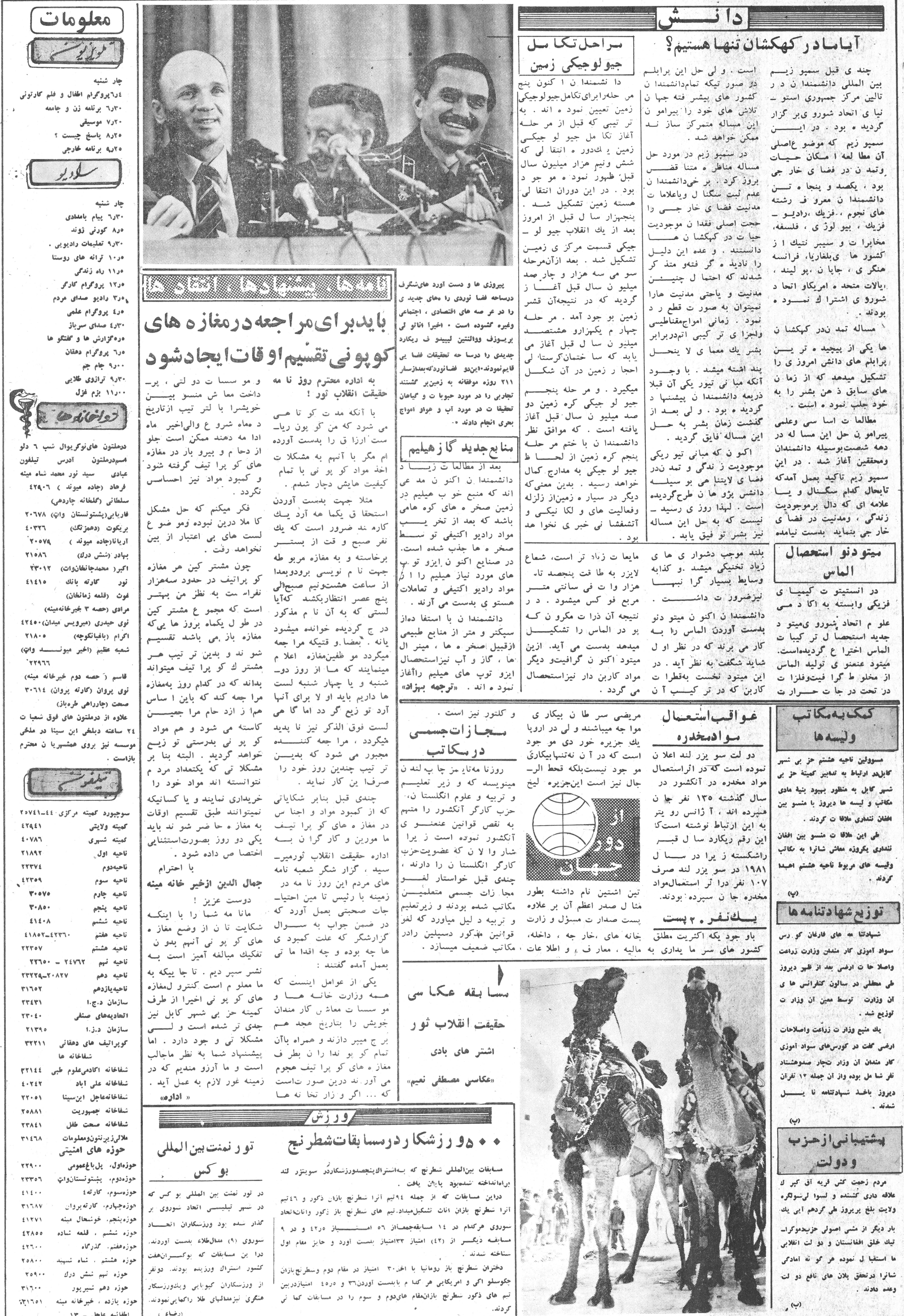

